\title{
Conditional Deletions of Epilepsy-Associated KCNQ2 and KCNQ3 Channels from Cerebral Cortex Cause Differential Effects on Neuronal Excitability
}

\author{
Heun Soh, Rima Pant, Joseph J. LoTurco, and Anastasios V. Tzingounis \\ Department of Physiology and Neurobiology, University of Connecticut, Storrs, Connecticut 06269
}

KCNQ2 and KCNQ3 potassium channels have emerged as central regulators of pyramidal neuron excitability and spiking behavior. However, despite an abundance of evidence demonstrating that KCNQ2/3 heteromers underlie critical potassium conductances, it is unknown whether KCNQ2, KCNQ3, or both are obligatory for maintaining normal pyramidal neuron excitability. Here, we demonstrate that conditional deletion of Kcnq2 from cerebral cortical pyramidal neurons in mice results in abnormal electrocorticogram activity and early death, whereas similar deletion of Kcnq3 does not. At the cellular level, Kcnq2-null, but not Kcnq3-null, CA1 pyramidal neurons show increased excitability manifested as a decreased medium afterhyperpolarization and a longer-lasting afterdepolarization. As a result, these Kcnq2-deficient neurons are hyperexcitable, responding to current injections with an increased number and frequency of action potentials. Biochemically, the Kcnq2 deficiency secondarily results in a substantial loss of KCNQ3 and KCNQ5 protein levels, whereas loss of Kcnq3 only leads to a modest reduction of other KCNQ channels. Consistent with this finding, KCNQ allosteric activators can still markedly dampen neuronal excitability in Kcnq3-null pyramidal neurons, but have only weak effects in Kcnq2-null pyramidal neurons. Together, our data reveal the indispensable function of KCNQ2 channels at both the cellular and systems levels, and demonstrate that pyramidal neurons have near normal excitability in the absence of KCNQ3 channels.

Key words: BFNC; epilepsy; KCNQ2; KCNQ3; M current

\section{Introduction}

The five members of the KCNQ family of potassium channels play important roles in neuronal physiology. Within the cerebral cortex, KCNQ channels have emerged as critical regulators of pyramidal neuron excitability and spiking behavior. In neurons, KCNQ channels are best known for their role in mediating the classical $\mathrm{M}$ current, a potassium conductance that increases as neurons approach action potential (AP) threshold (Wang et al., 1998; Jentsch, 2000). KCNQ channels, together with HCN and SK potassium channels, comprise the medium afterhyperpolarization (AHP), an inhibitory conductance elicited by a burst of APs (Gu et al., 2005, 2008). Consistent with these roles, experimentally blocking of KCNQ channels modulates spiking activity by converting simple spikes to high-frequency bursts and attenuating spike-frequency adaptation (Yue and Yaari, 2004; Otto et al., 2006). Accordingly, patients with loss-of-function and missense mutations in some KCNQ channels develop mild to very

Received Sept. 12, 2013; revised Feb. 11, 2014; accepted March 7, 2014.

Author contributions: H.S. and A.V.T. designed research; H.S., R.P., and J.J.L. performed research; H.S., J.J.L., and A.V.T. analyzed data; H.S., J.J.L., and A.V.T. wrote the paper.

This work was supported by National Institutes of Health grants to J.J.L. (D055655, MH056524) and A.V.T. (NS073981). We thank Icagen (Pfizer) for the gift of ICA-27243. We thank Drs. Karen Menuz, Jacques Wadiche, and Anna Lisa Lucido, and members of the Tzingounis laboratory for discussions and reading the manuscript.

The authors declare no competing financial interests.

Correspondence should be addressed to Anastasios Tzingounis, PhD, Department of Physiology and Neurobiology, University of Connecticut, Storrs, CT 06299. E-mail: anastasios.tzingounis@uconn.edu.

DOI:10.1523/JNEUROSCI.3919-13.2014

Copyright $\odot 2014$ the authors $\quad 0270-6474 / 14 / 335311-11 \$ 15.00 / 0$ severe pediatric epilepsy (Charlier et al., 1998; Singh et al., 1998; Ishii et al., 2012; Weckhuysen et al., 2012).

Of the five currently identified KCNQ family members, KCNQ2 and KCNQ3 are highly expressed in cerebral cortical pyramidal neurons and form the M current (Cooper et al., 2001). Multiple lines of evidence suggest that KCNQ2 and KCNQ3 exist and function primarily as heteromeric KCNQ2/3 channels, as the pharmacology of the M current best matches that of KCNQ2/3 heteromers coexpressed in heterologous cells (Wang et al., 1998). Furthermore, KCNQ2 and KCNQ3 channels express poorly in heterologous cells when alone, but robustly when they are coexpressed (Jentsch, 2000). In vivo, overexpression of a KCNQ2 dominant-negative subunit in transgenic mice significantly reduced the M current and caused elevated excitability and seizures (Peters et al., 2005). This dominant-negative subunit heteromerizes with KCNQ3 subunits and may eliminate all KCNQ2/3 function. Similarly, mice carrying missense Kcnq2 or Kcnq3 mutations identified in patients with benign familial neonatal convulsions (BFNCs) exhibited seizures (Singh et al., 2008).

These findings support a model in which both KCNQ2 and KCNQ3 are required for pyramidal neurons to control their excitability. However, the particularly high frequency of identified Kcnq2 mutations in both mild and very severe forms of pediatric epilepsy raises the possibility that while KCNQ3 is involved in maintaining normal excitability in pyramidal neurons, KCNQ2 is obligatory. However, directly testing this hypothesis by com- 
paring neuronal excitability in Kcnq2 and Kcnq3 knock-out mice was until now not feasible, due to the perinatal lethality of Kcnq2 knock-out mice (Watanabe et al., 2000).

Here, we generated transgenic mice with conditional deletion of Kcnq2 or Kcnq3 in cerebral cortical pyramidal neurons and report that these mice exhibit strikingly different phenotypes. Pyramidal neurons lacking Kcnq2 are hyperexcitable and have a smaller medium afterhyperpolarization (mAHP) and a prolonged afterdepolarization (ADP). By contrast, those pyramidal neurons lacking Kcnq3 are not hyperexcitable and have a near normal mAHP and ADP. Furthermore, conditional deletion of Kcnq2 but not Kcnq3 greatly reduces the protein levels of other KCNQ channels. These changes may explain why Kcnq2 conditional knock-out mice uniquely exhibit aberrant cortical activity and death by the third week of life. Therefore, our work demonstrates that proper control of pyramidal neuron excitability requires the presence of KCNQ2 but not KCNQ3 channels.

\section{Materials and Methods}

All experiments were performed according to the guidelines of the University of Connecticut-Storrs Institutional Animal Care and Use Committee.

Animals and genotyping. Kcnq2 and Kcnq3 conditional knock-out mice were generated using the Cre/loxP system by the Gene Targeting and Transgenic Facility of the University of Connecticut Health Center. Briefly, the targeting vector containing a neomycin cassette was electroporated into embryonic stem (ES) cells, and cells in which homologous recombination occurred were selected by neomycin resistance. These ES cells were injected into mouse embryos to obtain chimeric male mice, which were then used to generate $K c n q 2^{f l}$ and $K c n q 3^{f l}$ founder mice. The neomycin cassette, flanked by Frt sites, was then removed from all cells, including the germline, by FLPe recombinase, using the ROSA26-Flpe mice maintained in a C57BL/6 background. For our studies, we used the progeny of these mice, which lack the neomycin cassette in all somatic and germline cells. We refer to these as Kcnq2 $2^{f l /+}$ and $\mathrm{Kcnq}^{3^{f l /+}}$ mice. The floxed mice in a C57BL/6 background were then crossed with the Emx1-ires-cre recombinase strain, also in a C57BL/6 background (Jackson Laboratory), to obtain cerebral cortex-specific deletion of KCNQ channels.

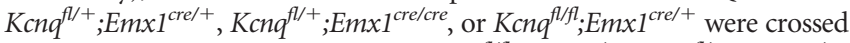
again to obtain the desired genotype. $K_{c n} q^{f / f} ; E m x 1^{+/+}, K_{c n} q^{f l /+} ; E m x 1^{+/+}$, $\mathrm{Kcnq}^{+/+} ; \mathrm{Emxl}^{\mathrm{cre} /+}, \mathrm{Kcnq}^{+/+} ; \mathrm{Emxl}^{\text {cre/cre }}$, or $\mathrm{Kcnq}^{+/+} ; \mathrm{Emxl}^{+/+}$were used as control mice. Kcn ${ }^{f l / f l} ; E m x 1^{\text {cre } /+}$ and $K c n q^{f l / f l} ; E m x 1^{\text {cre/cre }}$ were considered conditional knock-out mice. For genotyping Kcnq2-floxed mice, two primers were included in each PCR: Kcnq2 frt forward 5' CCACTTGGTGATGGACTGTG-3' ${ }^{\prime}$, and Kcnq2 frt reverse $5^{\prime}$-GCCTGTGTTTTCCATTTGCT- $3^{\prime}$. The primers amplified a $483 \mathrm{bp}$ fragment from the wild-type allele and a 581 bp product from the floxed allele. For Kcnq3-floxed mice, two primers were also included in each PCR: Kcnq3 frt forward 5'-CAGCACTCCCATGACAAATG-3', and Kcnq 3 frt reverse 5'-TCTCCCATGGCAAGTATTCC-3'. The primers amplified a $255 \mathrm{bp}$ fragment from the wild-type allele and a $339 \mathrm{bp}$ product from the floxed allele (Fig. 1A). To identify mice carrying Emx1-ires-cre, four primers were used in each PCR: cre forward 5'-GATCTCCGGTATTGAAACT CCAGC-3'; cre-reverse 5'-GCTAAACATGCTTCATCGTCGG-3'; Emx1-ires-cre wild-type forward 5'-AAGGTGTGGTTCCAGAATCG-3'; and Emx1-ires-cre wild-type reverse 5'-CTCTCCACCAGAAGGC TGAG- $3^{\prime}$. The primers amplified a $750 \mathrm{bp}$ fragment in mice carrying the cre allele and a $378 \mathrm{bp}$ fragment from the wild-type allele.

Western blotting. For Western blotting, mice [postnatal day (P) 15P21] were anesthetized with isoflurane (Baxter Healthcare) and rapidly decapitated. Hippocampi were quickly removed and homogenized with a rotor-stator homogenizer in ice-cold $320 \mathrm{~mm}$ sucrose solution supplemented with protease inhibitor mixture and PMSF (1 mM) (SigmaAldrich). Hippocampi that were not used immediately were snap-frozen in liquid nitrogen and kept at $-80^{\circ} \mathrm{C}$ until further use. Following homogenization and centrifugation $\left(1000 \times \mathrm{g}, 10 \mathrm{~min}\right.$ at $\left.4^{\circ} \mathrm{C}\right)$ of the hippocampi, the supernatant was collected and further centrifuged $\left(16,100 \times g, 45 \mathrm{~min}\right.$ at $\left.4^{\circ} \mathrm{C}\right)$ to isolate a crude membrane fraction. The resultant pellet was resuspended in 5\% SDS RIPA buffer (SigmaAldrich). Protein concentration was then determined using the BCA assay (Thermo Fisher Scientific). A total of $200-400 \mu \mathrm{g}$ of protein per lane was separated on reducing 7.5-10\% SDS-polyacrylamide gels and transferred to PVDF membranes. Following transfer to PVDF membranes and before incubation with primary antibodies, we cut the membranes in half between the 75 and $50 \mathrm{KDa}$ molecular protein standards (Liu and Fagotto, 2011). The higher molecular weight-containing membranes were probed with rabbit anti-KCNQ2 (1:200; Sigma-Aldrich), anti-KCNQ3 (1:200; Alomone Labs), or anti-KCNQ5 (1:200; Santa Cruz Biotechnology), whereas the lower molecular weight-containing membranes were probed with anti- $\beta$-actin (1:5000; Sigma-Aldrich). On occasion, PVDF membranes were stripped using the NewBlot PVDF stripping buffer (Li-Cor Biosciences) and reprobed. Protein was detected by infrared-labeled secondary antibodies (Thermo Fisher Scientific). Specifically, we visualized the mouse anti- $\beta$-actin with a goat anti-mouse fluorophore 680-conjugated secondary antibody, whereas the antiKCNQs were visualized with an anti-rabbit fluorophore 800-conjugated secondary antibody. Both membranes were scanned simultaneously using the Odyssey imaging system (Li-Cor Biosciences; two-color Western blot detection with infrared fluorescence). KCNQ protein band intensities were normalized to the $\beta$-actin loading control.

Slice preparation and electrophysiology. Transverse slices of the hippocampus were prepared from P15-P20 mice. Briefly, mice were anesthetized using isoflurane (Baxter Healthcare) and rapidly killed by decapitation. The brain was quickly removed and placed in ice-cold cutting solution consisting of the following: $25 \mathrm{~mm} \mathrm{NaHCO}, 200 \mathrm{~mm}$ sucrose, $10 \mathrm{~mm}$ glucose, $2.5 \mathrm{~mm} \mathrm{KCl}, 1.3 \mathrm{~mm} \mathrm{NaH} \mathrm{PO}_{4}, 0.5 \mathrm{mM} \mathrm{CaCl}_{2}$, and $7 \mathrm{mM} \mathrm{MgCl}_{2}$. The cerebellum, prefrontal lobe, and temporal lobe were removed and $300 \mu \mathrm{m}$ transverse hippocampal slices, including the surrounding structures, were cut using a vibratome (Microm HM $650 \mathrm{~V}$, Thermo Fisher Scientific). Slices were then transferred to a holding chamber containing artificial CSF (ACSF) consisting of the following: $125 \mathrm{~mm} \mathrm{NaCl}, 26 \mathrm{~mm} \mathrm{NaHCO}_{3}, 2.5 \mathrm{~mm} \mathrm{KCl}, 1 \mathrm{~mm} \mathrm{NaH} \mathrm{PO}_{4}, 1.3 \mathrm{~mm}$ $\mathrm{MgCl}_{2}, 2.5 \mathrm{mM} \mathrm{CaCl}_{2}$, and $12 \mathrm{~mm}$ glucose. Slices were first equilibrated at $35^{\circ} \mathrm{C}$ for $30 \mathrm{~min}$ and maintained at room temperature $\left(\sim 22^{\circ} \mathrm{C}\right)$ for $\geq 1 \mathrm{~h}$ before any electrophysiological recordings. The cutting and holding solutions (ACSF) were saturated with $95 \% \mathrm{O}_{2}$ and $5 \% \mathrm{CO}_{2}$.

All experiments were performed at room temperature. Whole-cell recordings were obtained using electrodes pulled from thin-walled borosilicate glass capillaries having resistances between 2.5 and $4.5 \mathrm{M} \Omega$ when filled with recording solution as described below (World Precision Instruments). Pyramidal cells from the CAl area of the hippocampus were visually identified with infrared differential interference contrast optics using a $60 \times$ water-immersion objective lens on an upright microscope (Olympus BX51, Olympus). The internal recording solution for wholecell recording consisted of the following: $130 \mathrm{~mm}$ potassium methylsulfate, $10 \mathrm{~mm} \mathrm{KCl}, 10 \mathrm{~mm}$ HEPES, $20 \mathrm{~mm}$ inositol, $4 \mathrm{~mm} \mathrm{NaCl}, 4 \mathrm{~mm}$ $\mathrm{Mg}_{2} \mathrm{ATP}$, and $0.4 \mathrm{~mm} \mathrm{Na}_{4} \mathrm{GTP}$ (osmolarity, 300-305 mOsm). The $\mathrm{pH}$ was adjusted to 7.25-7.3 with $\mathrm{KOH}$. ACSF was used as an internal recording solution for the cell-attached recordings. For recordings of the M current, the extracellular solution also included TTX (500 nM; Alomone Labs), 4-AP (2 mM), CsCl (1 mM), $\mathrm{CdCl}_{2}(100 \mu \mathrm{M})$, and apamin (100 nM) to block, respectively, voltage-gated sodium and calcium channels as well as calcium-activated SK channels, HCN channels, and A-type potassium channels (Sigma-Aldrich). CNQX (4 $\mu \mathrm{M})$, APV (10 $\mu \mathrm{M})$, and picrotoxin $(100 \mu \mathrm{M})($ Abcam) were present in experiments to block AMPAmediated, NMDA-mediated, and GABA-mediated synaptic transmission, respectively (with the exception of the data presented in Figs. $2 A$, $5 B)$. A calculated liquid junction potential of $-6.5 \mathrm{mV}$ was used when measuring the resting membrane potential (RMP) and AP threshold. RMP was measured in current clamp with zero holding current. AP threshold was defined as the membrane potential at which the AP rate of rise reached $50 \mathrm{mV} / \mathrm{ms}$. All recordings were performed using a Multiclamp 700B amplifier (Molecular Devices), low-pass-filtered at $2 \mathrm{kHz}$, and sampled at $10 \mathrm{kHz}$. Data were analyzed offline using Axograph X (Axograph), Clampfit (Molecular Devices), Origin (OriginLab), or Spike2 (Cambridge Electronic Design) software. 
A

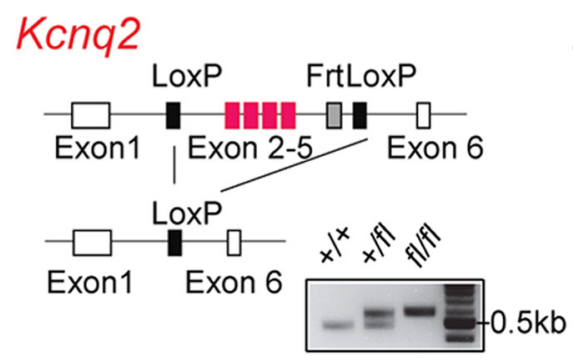

C

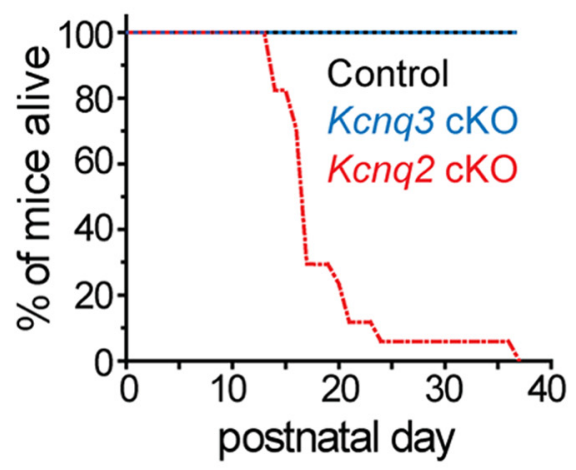

B

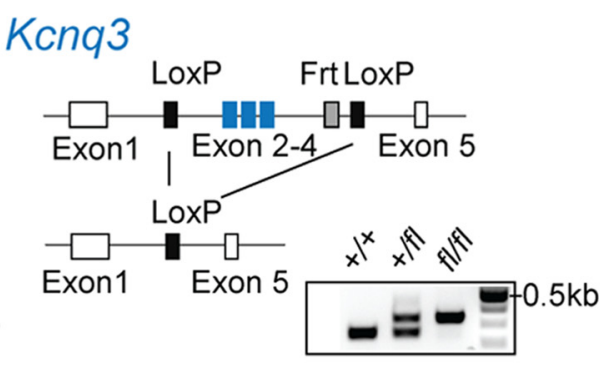

D

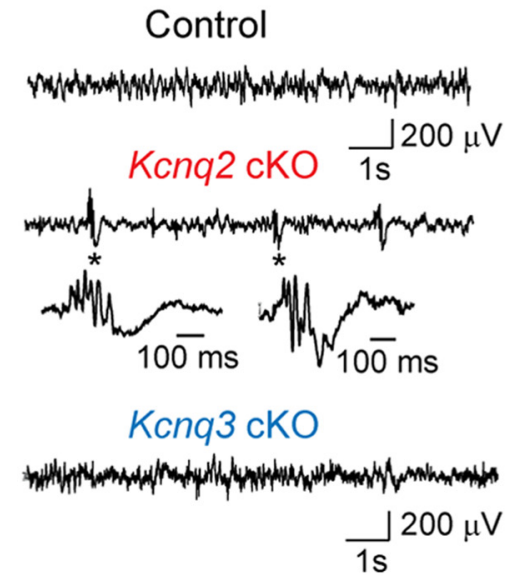

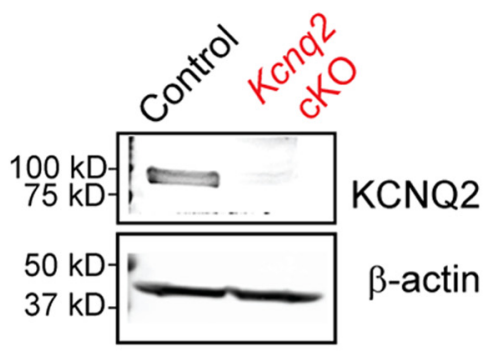

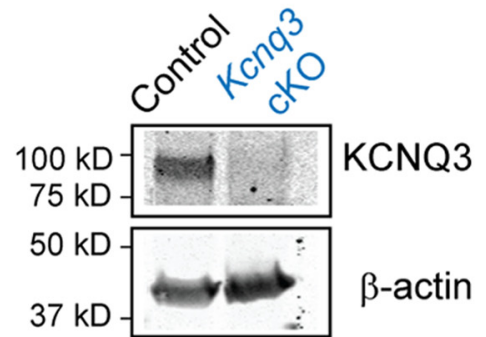

Figure 1. Contrasting the effects of $K c n q 2$ and $K c n q 3$ conditional deletion on survival and ECOG activity. A, Targeting strategy for generation of $K c n q 2^{f l f t}$ and $K c n q 3^{f l f t}$ mice. Targeted axons (red,

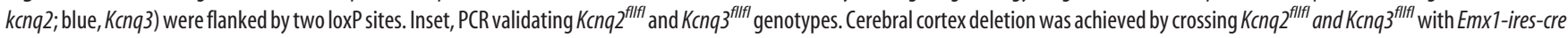
(Emx1) mice. $\boldsymbol{B}$, Immunoblot analysis of hippocampal membrane fractions of KCNQ2 or KCNQ3 from cerebral cortex-specific Kcnq2 $2 K 0$ and Kcnq3 CKO mice. Levels of KCNQ2 and KCNQ3 are reduced by $\sim 80 \%$ in the $K c n q 2 c K O(n=8)$ and $K c n q 3 c K O(n=7)$ mice, respectively. C, Survival curves of control (black, $n=10), K c n q 2 c K O$ (red, $n=17)$, and $K c n q 3 c K O$ (blue, $n=8)$ mice. The survival graphs show that most Kcnq2 $c K 0$ mice die prematurely between P15 and P20. Control and Kcnq3 $c K 0$ mice did not die during the same time period. D, Left, Representative ECoG recordings from control, Kcnq2 $\mathrm{cKO}$, and $K \mathrm{cnq} 3 \mathrm{CKO}$ mice. Representative polyspike events were indicated by asterisk from Kcnq2 $\mathrm{cKO}$ and shown in extended time scale. Right, Polyspike events were counted every 30 s during the first 15 min of recordings from control (black, $n=5 ;$ P15-P19), Kcnq2 cKO (red, $n=4$, P15-P19), and Kcnq3 $c K 0$ (blue, $n=5$, P16-P19) mice.

Electrocorticography recordings. Subdural EEG electrodes were implanted in young mice (P15-P19). The recording electrodes used were modified with machine contact gold-plated miniature dip sockets 250 $\mu \mathrm{m}$ in diameter (Newark Electronics). Two electrodes were implanted in each pup relative to bregma: one was placed anterior $2 \mathrm{~mm}$, left $1 \mathrm{~mm}$ (approximately the level of frontal cortex olfactory bulb border), and the other was placed posterior $1 \mathrm{~mm}$, right $1 \mathrm{~mm}$, within the somatosensory cortex. The electrodes were implanted at a depth of $\sim 0.7 \mathrm{~mm}$ from the skull surface. Electrodes were secured to the skull with cyanoacrylic (VetBond) and dental cement. Differential voltage signals with the frontal left electrode as reference were amplified $1000 \times$ with a DAM-50 differential amplifier ( $1 \mathrm{~Hz}$ low filter, $10 \mathrm{kHz}$ high filter). Amplified signals were digitized at $5 \mathrm{kHz}$, acquired, and displayed continuously (Labchart 7, ADInstruments). EEGs were recorded immediately after pups recovered from anesthesia and recordings were made for $1-2 \mathrm{~h}$. We analyzed data from recordings in which the investigator was blind to the genotype. We considered polyspike episodes events that exhibited $\geq 2$ spikes followed by a wave.

Statistical analysis. Data are displayed as means \pm SEM, and significance was determined with either one-way ANOVA or two-way repeated-measures ANOVA using either OriginLab or Prism (Graphpad). The $n$ values indicate number of cells.

\section{Results}

Deletion of Kcnq2, but not of Kcnq3, from cerebral cortical pyramidal neurons leads to cortical hyperexcitability and early death

To overcome the perinatal lethality of constitutive Kcnq2 knockout mice and minimize any secondary effects of deleting KCNQ channels throughout the nervous system, we used the Cre/loxP system to generate conditional Kcnq2 and Kcnq3 knock-out mice. In the Cre/loxP system, controlled expression of Cre recombinase allows for recombination of two loxP sites, thus excising the intervening genomic sequence. We developed mice in which exons 2-5 of the Kcnq2 gene and exons 2-4 of the Kcnq3 gene are flanked by loxP sites and confirmed the floxed sequences by PCR (Kcnq $f^{f l l f l}$ and Kcnq $3^{\text {fllfl }}$ mice; Fig. 1A). Cre excision of the floxed exons both removes the pore regions of the KCNQ2 and KCNQ3 channels and introduces a frame-shift mutation. If translation of the altered mRNAs occurs, only the very $\mathrm{N}$-terminal regions of the channels would be translated. 
To generate pyramidal neuronspecific Kcnq2 conditional knock-out (Kcnq2 $\mathrm{KOO}$ ) or Kcnq3 conditional knockout (Kcnq3 cKO) mice, we crossed the $K c n q 2^{\text {fllfl }}$ and $K c n q 3^{\text {fllfl }}$ mice to Emx1-irescre $(E m \times 1)$ mice, which express Cre recombinase in neocortical and hippocampal pyramidal neurons during neurogenesis (embryonic day 10.5; Gorski et al., 2002). Conditional deletion of either Kcnq2 or Kcnq3 led to a significant reduction in KCNQ2 $(76 \pm 6.4 \%, n=8)$ and KCNQ3 $(76 \pm 7.0 \%, n=7)$ protein levels, respectively, in hippocampal membrane fractions of conditional knock-out compared with control mice (Fig. 1B). Previous work has shown that Emx1-targeted Cre recombinase leads to excision of floxed sequences in $\sim 88 \%$ of pyramidal neurons, but does not excise floxed sequences in interneurons, consistent with the Emx1 expression pattern (Gorski et al., 2002; Ballester-Rosado et al., 2010). Considering that most KCNQ2 and KCNQ3 protein in the cerebral cortex is expressed by pyramidal neurons, but that these channels are also present in some parvalbuminexpressing and somatostatin-expressing interneurons (Cooper et al., 2001; Lawrence et al., 2006; Nieto-Gonzalez and Jensen, 2013), our observations are in agreement with predictions for the Emx1-Cre line.

Constitutive Kcnq2 knock-out mice die soon after birth (Watanabe et al., 2000), while constitutive Kcnq3 knockout mice survive into adulthood ( $\mathrm{Tz}-$ ingounis and Nicoll, 2008). In the case of Kcnq3, we found that, similar to the constitutive knock-out, Kcnq3 cKO mice also lived into adulthood (Fig. 1C). In contrast, conditional deletion of Kcnq2 permitted survival until the third week of life (Fig. 1C). During the course of our studies, we witnessed a Kcnq2 cKO mouse that underwent a severe tonic-clonic seizure followed by premature death. Closer observation of other Kcnq2 $c K O$ mice revealed unusual behaviors that could be consistent with seizures, such as rearing, jumping, and falling. No such behaviors were observed with either Kcnq2 heterozygous or Kcnq3 $c \mathrm{KO}$ mice.

To directly inspect for aberrant cerebral cortical activity, we performed surface electrocorticography recordings (ECoGs) from control, Kcnq2 $c K O$, and Kcnq3 $c K O$ mice. We then analyzed the initial $15 \mathrm{~min}$ of the recordings blind to the genotype. ECoGs from Kcnq2 cKO mice exhibited episodes of polyspike events (Fig. 1D) reaching to $\sim 100$ events within the first $15 \mathrm{~min}(92 \pm$ 15 events, $n=4)$ compared with hardly any events in control and Kcnq3 cKO mice (control: $3.4 \pm 3$ events, $n=5$; Kcnq3 cKO: $2.4 \pm 1.2$ events, $n=5$ ). The polyspike events showed multiple repetitive spikes typically followed by a wave of variable duration (Fig. 1D). Episodes lasted between 100 and $300 \mathrm{~ms}$ and occurred with an average frequency of $6.1 \pm 1$ events per minute $(n=4$ mice). These data indicate that deletion of KCNQ2 channels leads to elevated cortical excitability. Such hyperexcitability might be due to an imbalance in excitatory and inhibitory network activity caused by the selective removal of Kcnq2 from pyramidal neurons, and may contribute to the postnatal lethality of Kcnq2 cKO mice.

\section{Differential dependence of the M current and mAHP on KCNQ2 and KCNQ3}

We examined the effect of deleting KCNQ2 and KCNQ3 channels on pyramidal neuron excitability, focusing on hippocampal CA1 pyramidal neurons, because they are a good model system for cerebral cortex KCNQ channel activity (Peters et al., 2005; Otto et al., 2006; Singh et al., 2008). First, we determined whether the M current, a well established KCNQ2/3 current, was decreased in the conditional knock-out mice. The $\mathrm{M}$ current was obtained by first voltage-clamping neurons to $-20 \mathrm{mV}$ to open KCNQ channels and inactivate delayed rectifier potassium channels, followed by hyperpolarization to $-55 \mathrm{mV}$ to deactivate KCNQ channels. This standard M-current protocol was then repeated in the presence of $20 \mu \mathrm{M}$ XE991, a concentration that leads to an almost complete block of KCNQ2/3 channels (Wang et al., 1998). The M current was then defined as the XE991-sensitive difference current (Fig. 2A). Deletion of either Kcnq2 or Kcnq3 led to a substantial loss of the M current ( $\sim 85$ and $\sim 50 \%$ respectively; controls, $104 \pm 15 \mathrm{pA}, n=8 ;{ }^{* *} K c n q 2 c K O, 15 \pm 9 \mathrm{pA}, n=9 ;{ }^{*} K c n q 3 c K O$, $49 \pm 13 \mathrm{pA}, n=9 ;{ }^{*} p<0.05{ }^{* *} p<0.001$ vs controls, ANOVATukey's post hoc test; Fig. $2 A$ ). This finding is consistent with 
A
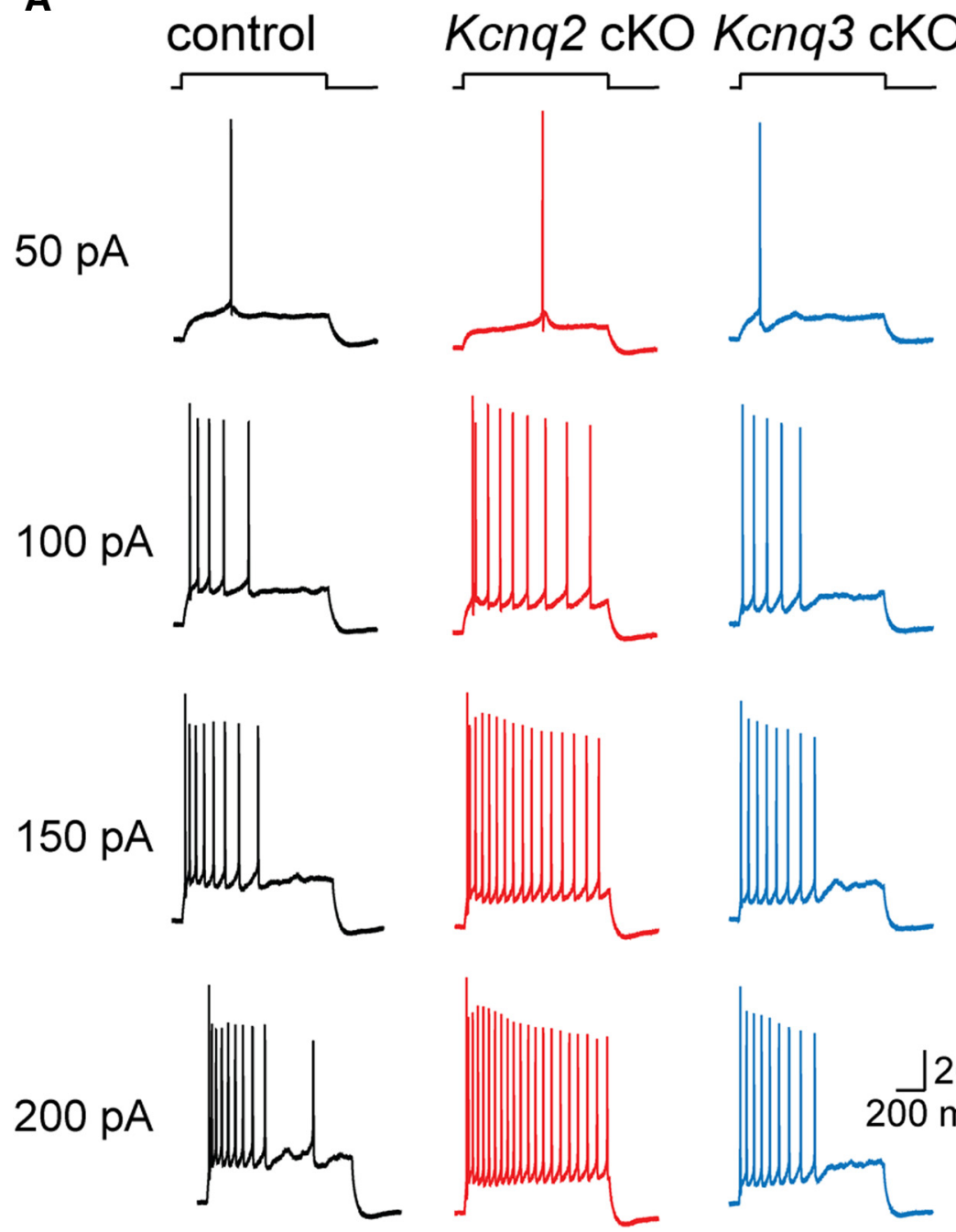

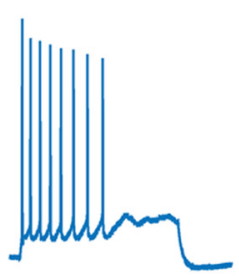

B
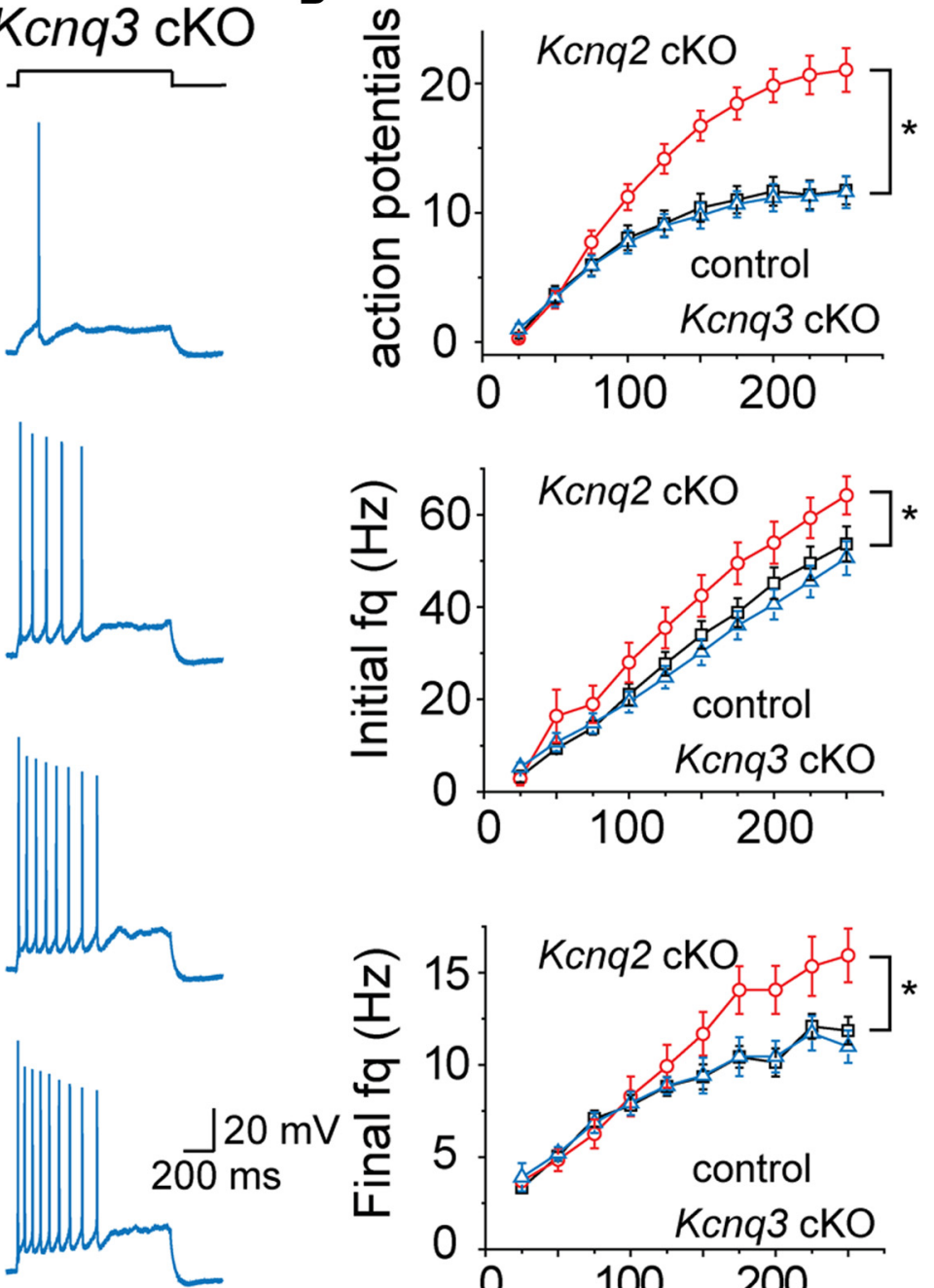

Figure 3. Elevated neuronal excitability of CA1 pyramidal neurons in Kcnq2-null but not Kcnq3-null neurons. A, Voltage responses to various current injection steps (1 s) in pyramidal neurons from either control $(n=18), K c n q 2 C K O(n=18)$, or $K c n q 3 c K O(n=18)$ mice. Membrane potential was kept at $-60 \mathrm{mV}$ by injecting a small $D C$ current through the recording pipette. Representative traces showing the effects of deleting either $K c n q 2$ (red) or $K c n q 3$ (blue) on pyramidal neuron excitability. $\boldsymbol{B}$, Summary graphs showing the effect of $K c n q 2$ or Kcnq3 deletion on CA1 pyramidal neuron AP number, initial firing frequency, and final firing frequency. Data shown are means \pm SEM. Statistical significance was determined by two-way repeated-measures ANOVA ( $\left.{ }^{*} p<0.05\right)$.

previous studies indicating that the $\mathrm{M}$ current is mediated by both KCNQ2 and KCNQ3 channels (Wang et al., 1998).

We next examined the contributions of KCNQ2 and KCNQ3 to the $\mathrm{mAHP}$, a conductance that also requires the presence of KCNQ2/3 heteromers (Peters et al., 2005). We elicited the mAHP using a large depolarizing pulse (50 ms, $1 \mathrm{nA}$ ) in neurons currentclamped close to their RMP (Fig. 2B). To avoid any possible contamination from calcium-activated SK channels, the SK channel blocker apamin (100 nM) was included in the extracellular solution. An mAHP developed in control mice following the termination of the $50 \mathrm{~ms}$ depolarizing step, and Kcnq3 $\mathrm{cKO}$ pyramidal neurons had an $\mathrm{mAHP}$ of similar peak amplitude (Fig. $2 B$ ). In contrast, deletion of $K c n q 2$ led to a $>50 \%$ reduction of the mAHP (Fig. $2 B$; control, $4.8 \pm 0.6 \mathrm{mV}, n=12 ;{ }^{* *} \mathrm{Kcnq} 2 \mathrm{cKO}$, $2.1 \pm 0.3 \mathrm{mV}, n=12 ; \mathrm{Kcnq} 3 \mathrm{cKO}, 4.2 \pm 0.6 \mathrm{mV}, n=12 ;{ }^{* *} p<$ 0.001 vs control, ANOVA-Tukey's post hoc test). This differential contribution of KCNQ2 and KCNQ3 was unexpected given their similar role in the $\mathrm{M}$ current. Therefore, we also measured the
mAHP with a different protocol, using a depolarization pulse (100 ms) of a magnitude adjusted to elicit 4-5 APs. Again we found that the mAHP in Kcnq2 $c K O$ mice was significantly reduced, unlike the mAHP in Kcnq3 $c K O$ mice (control, $4.4 \pm 1$ $\mathrm{mV}, n=8 ;{ }^{* \star} \mathrm{Kcnq} 2 \mathrm{cKO}, 1.4 \pm 0.4 \mathrm{mV}, n=9 ; K c n q 3 \mathrm{cKO}, 3.7 \pm$ $0.3 \mathrm{mV}, n=8$; ${ }^{*} p<0.001$ vs control, ANOVA-Tukey's post hoc test). Last, we repeated our $\mathrm{mAHP}$ experiments using a protocol that controlled for both the number and timing of APs. We induced five APs, each with a short $2 \mathrm{~ms}$ pulse in either $20 \mathrm{~ms}$ (50 $\mathrm{Hz})$ or $10 \mathrm{~ms}$ intervals $(100 \mathrm{~Hz})$. As with our previous measurements, we found that the mAHP critically depends on the presence of KCNQ2 channels, but not of KCNQ3 channels. The reduction in the mAHP seen in Kcnq2 $c K O$ was independent of the stimulation frequency ( $50 \mathrm{~Hz}$ : control, $2.2 \pm 0.1 \mathrm{mV}, n=6$; ${ }^{* *} \mathrm{Kcnq} 2 \mathrm{cKO}, 0.8 \pm 0.3 \mathrm{mV}, n=7 ; \mathrm{Kcnq} 3 \mathrm{cKO}, 3.0 \pm 0.4 \mathrm{mV}, n=$ $8 ;{ }^{* *} p<0.005$ vs control; $100 \mathrm{~Hz}$ : control, $2.4 \pm 0.2 \mathrm{mV}, n=6$; ${ }^{*} K c n q 2 c K O, 1.2 \pm 0.3 \mathrm{mV}, n=7 ; K c n q 3 c K O, 2.9 \pm 0.45 \mathrm{mV}$, $n=8 ;{ }^{* *} p<0.01$ vs control, ANOVA-Tukey's post hoc test). 
In CA1 pyramidal neurons, a prominent ADP develops following an AP elicited by a brief suprathreshold stimulus (Bean, 2007). Because the ADP is limited by the MAHP (Yue and Yaari, 2004, 2006), we predicted that the ADP would be of greater duration in Kcnq2 cKO neurons compared with those lacking Kcnq3. We current-clamped CA1 pyramidal neurons close to their RMPs and injected a brief current pulse ( $2 \mathrm{~ms}, 1 \mathrm{nA}$ ) to elicit a single AP followed by an ADP. Indeed, there was an almost twofold increase in the ADP in Kcnq2 cKO mice compared with control mice (Fig. 2C). In contrast, the ADP was not significantly increased in Kcnq3 cKO mice; if anything, it tended to be smaller than that of controls (control, $225 \pm 83 \mathrm{mV}^{\star} \mathrm{ms}, n=21 ;{ }^{\star} K c n q 2 c K O$, $526 \pm 70 \mathrm{mV}^{\star} \mathrm{ms}, n=19 ; \mathrm{Kcnq} 3 c \mathrm{KO}$, $33 \pm 90 \mathrm{mV}^{\star} \mathrm{ms}, n=11 ;{ }^{\star} p<0.05 \mathrm{vs}$ control, ANOVA-Tukey's post hoc test). This is likely due to the faster repolarization time course of the ADP in Kcnq3 cKO mice $\left(\mathrm{ADP}_{\text {decay }}\right.$ : control, $17 \pm 2.2 \mathrm{~ms}, n=$ 18; Kcnq2 cKO, $25 \pm 1.5 \mathrm{~ms}, n=19$; ${ }^{*} \mathrm{Kcnq} 3 \mathrm{cKO}, 12 \pm 1.8 \mathrm{~ms}, n=11 ;{ }^{*} p<$ 0.05 vs control, ANOVA-Tukey's post hoc test). These data demonstrate that the mAHP is highly dependent upon the presence of KCNQ2 channels, while the remaining KCNQ3 channels cannot fully compensate for the loss of KCNQ2 channels. They also demonstrate that, unlike the $\mathrm{M}$ current, the mAHP does not depend upon KCNQ3 channels.

\section{Loss of Kcnq2, but not Kcnq3, leads to elevated neuronal excitability}

The differential sensitivity of the mAHP to deletion of Kcnq2 versus Kcnq3 suggested that loss of KCNQ2 or KCNQ3 channels might have different effects on neuronal excitability. Therefore, we compared the excitability of CA1 pyramidal neurons from control, Kcnq 2 cKO, and Kcnq 3 cKO mice by examining the number of APs elicited by current injections of various amplitudes ( $1 \mathrm{~s}, 0$ to $+250 \mathrm{pA}$ ). Increasing the amplitude of the injected current led to a greater number of APs in all genotypes (Fig. 3). However, the number of APs was significantly greater in Kcnq2-null neurons compared with either control or Kcnq3-null neurons. As shown in Figure $3 A$, pyramidal neurons from Kcnq2 cKO mice fired throughout the duration of the depolarizing pulse, signifying a decreased level of spike frequency adaptation. When quantified, these Kcnq2-deficient neurons were found to have both a greater initial firing frequency and a greater final firing frequency compared with either control or Kncq3-null neurons (Fig. 3B).

\section{Intrinsic membrane properties in $K c n q 2$ cKO and $K c n q 3 c K O$} mice

In addition to the reduced $\mathrm{mAHP}$, a change in the intrinsic membrane properties of Kcnq2 $c K O$ pyramidal neurons might also
Kenq2 cKO Kcnq3 cKO
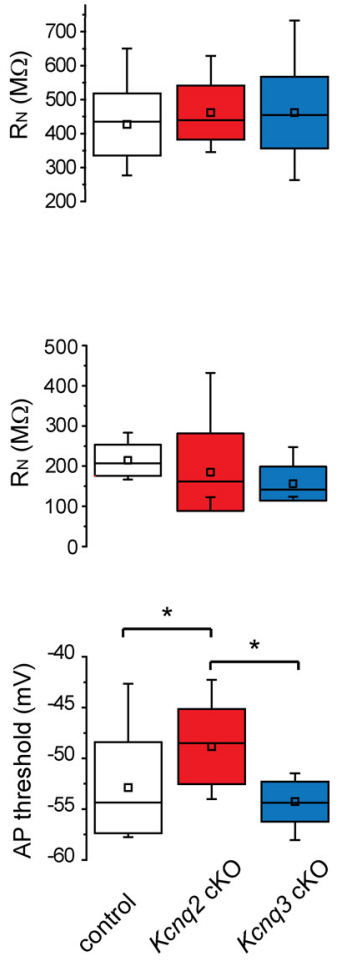

Figure 4. Contrasting the effects of Kcnq2 and Kcnq3 deletion on CA1 pyramidal neuron intrinsic properties. A, Left, Voltage responses to various current injection steps ( 1 s from 0 to $-100 \mathrm{pA}$ ) in pyramidal neurons from either control, $K c n q 2 \mathrm{cKO}$, or $K c \mathrm{cn}^{3}$ graphs showing the effect of deleting $K c n q 2$ or $K c n q 3$ on the $R_{\mathrm{N}}(n=21-26) . R_{\mathrm{N}}$ was determined by the slope of the line fitted to 列 time scale to show a burst of APs from Kcnq2 $K 0$ mice. Far right, Summary graph showing the effects of deleting Kcnq2 or Kcnq3 in the $R_{N}(n=7-9) . R_{N}$ was measured from the slope between $-63 \mathrm{mV}$ and the voltage before the first AP. C, Representative single symbol represents the mean value, and whiskers represent the minimum and maximum data value. Statistical significance was determined by one-way ANOVA $\left({ }^{*} p<0.05\right)$ using Tukey's as post hoc test.

contribute to their increased excitability. Indeed, pharmacologically blocking KCNQ channels in wild-type neurons increases their input resistance $\left(R_{\mathrm{N}}\right)$, which in turn increases neuronal excitability (Yue and Yaari, 2004; Shah et al., 2008). We determined the $R_{\mathrm{N}}$ of Kcnq-null neurons by giving a series of hyperpolarizing current injections to pyramidal neurons from control, Kcnq2 $c K O$, and Kcnq3 $c K O$ mice (Fig. 4A). No significant changes in the $R_{\mathrm{N}}$ were observed between the different genotypes $\left(R_{\mathrm{N}}\right.$ : control, $427 \pm 18 \mathrm{M} \Omega, n=26 ; K c n q 2 c K O, 462 \pm 17 \mathrm{M} \Omega, n=23 ;$ Kcnq3 $c K O, 462 \pm 23 \mathrm{M} \Omega, n=21 ; p>0.05$, ANOVA; Fig. $4 A)$. Given that KCNQ channels are primarily active close to spike threshold, we also measured $R_{\mathrm{N}}$ using a slow depolarizing ramp protocol (0.12 nA/s; Hu et al., 2007). As seen in Figure 4B, neurons from control, Kcnq2 $c K O$, and Kcnq3 $c K O$ mice had similar $R_{\mathrm{N}}$ 's up to AP threshold $\left(R_{\mathrm{N}}\right.$ : control, $215 \pm 4 \mathrm{M} \Omega, n=7 ;$ Kcnq2 $c K O, 185 \pm$ $10 \mathrm{M} \Omega, n=9 ; \mathrm{Kcnq3} c K O, 156 \pm 4 \mathrm{M} \Omega, n=7 ; p>0.05$, ANOVA). Consistent with their increased excitability, loss of KCNQ2 channels led pyramidal neurons to fire first in bursts when the depolarization ramp surpassed spike threshold (2.7 \pm 0.2 APs/burst; $n=9$; Fig. $4 B$ ). This is likely due to the loss of the $\mathrm{mAHP}$ and associated increased ADP in Kcnq2-null neurons. 


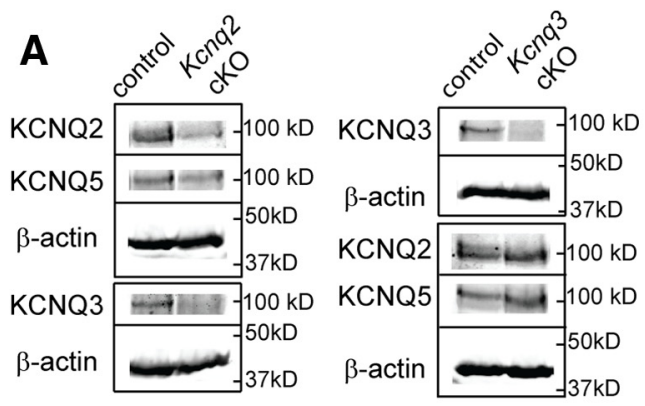

B
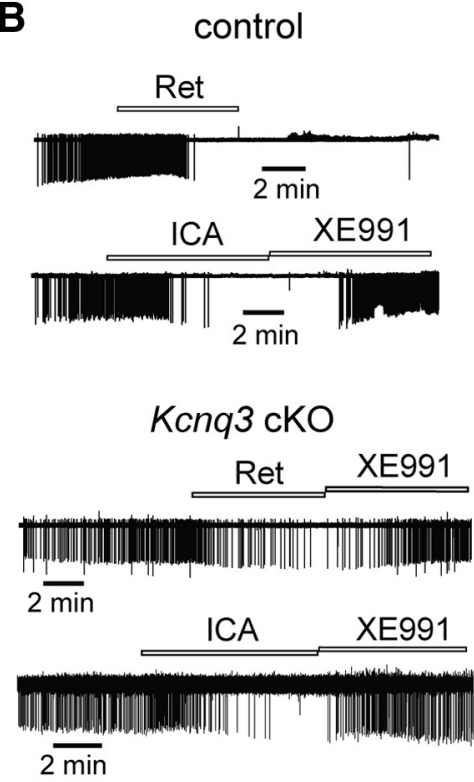

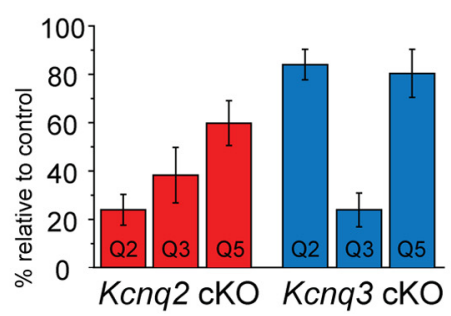

Konq2 cKO
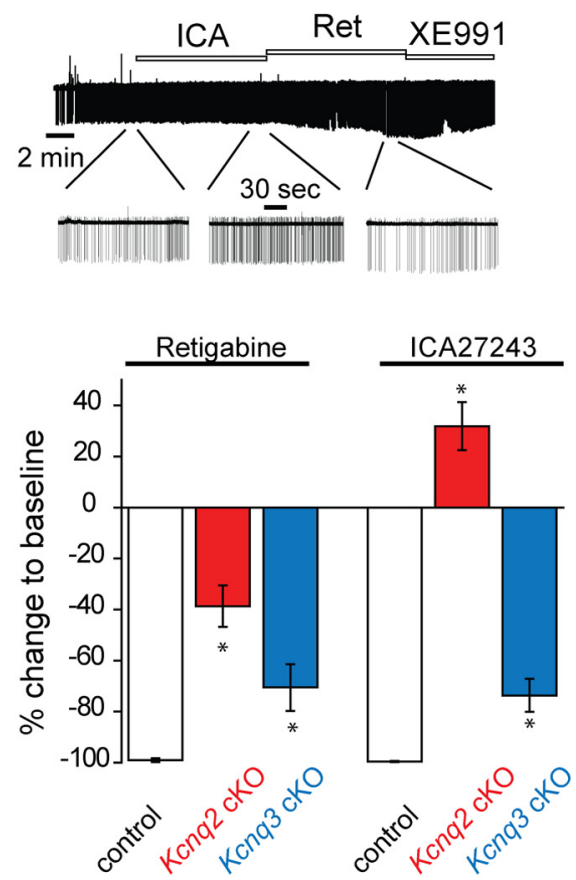

Figure 5. Contrasting the effects of deleting Kcnq2 and Kcnq3 on KCNQ channel levels and activity. A, Left, Hippocampal membrane fractions from the indicated mouse lines were probed with antibodies against KCNQ2, KCNQ3, or KCNQ5 channels. Western blots were also probed with a $\beta$-actin antibody as a protein loading control (detected between the 37 and $50 \mathrm{kDa}$ molecular weight standards; predicted molecular weight is $42 \mathrm{kDa}$ ). Right, Summary graph showing the change in KCNQ protein level in Kcnq2 $C K 0$ or Kcnq3 $c K 0$ mice in relation to control mice $(n=3-8)$. B, Sample traces of tonic firing activity in CA1 pyramidal neurons from the indicated mouse lines in the background presence of $8.5 \mathrm{~mm}\left[\mathrm{~K}^{+}\right]_{0}$, and following application of either retigabine (Ret; $20 \mu \mathrm{M})$, ICA-27243 (ICA; $25 \mu \mathrm{M})$, or XE991 $(20 \mu \mathrm{M})$. Left, Summary graph of firing rate changes induced by retigabine or ICA-27243 in either control, Kcnq2 cKO, or Kcnq3 $c K 0$ mice $(n=7-12)$. Cell-attached recordings took place in the voltage-clamp configuration. Data shown are means \pm SEM. Statistical significance was determined by one-way ANOVA $\left({ }^{*} p<0.05\right)$ using Dunnett's as post hoc test.

However, we were surprised to find that the threshold voltage for AP generation was shifted to more depolarized values in Kcnq2 $c K O$ mice (control, $-53 \pm 1.2 \mathrm{mV}, n=15 ;{ }^{\star} K c n q 2$ cKO, $-49 \pm 1.1 \mathrm{mV}, n=12 ; \mathrm{Kcnq} 3 \mathrm{cKO},-54 \pm 0.6 \mathrm{mV}, n=11 ;{ }^{*} p<$ 0.05, ANOVA-Tukey's post hoc test; Fig. 4C), an effect opposite of that predicted for the loss of a potassium channel. This shift was not accompanied by a decrease in AP amplitude (control, $105 \pm 1.0 \mathrm{mV}, n=15 ; \mathrm{Kcnq} 2 \mathrm{KKO}, 103 \pm 1.3 \mathrm{mV}, n=12$; Kcnq $3 c K O, 103 \pm 1.2 \mathrm{mV}, n=11 ; p>0.05$, ANOVA) or in a decrease in the maximum rate of AP activation (control, $265 \pm$ $9 \mathrm{mV} / \mathrm{ms}, n=15 ; \mathrm{Kcnq} 2 \mathrm{cKO}, 258 \pm 10 \mathrm{mV} / \mathrm{ms}, n=12 ; \mathrm{Kcnq} 3$ $c K O, 255 \pm 8 \mathrm{mV} / \mathrm{ms}, n=11 ; p>0.05$, ANOVA), suggesting that altered properties of voltage-gated sodium channels did not underlie the shift.

Two other intrinsic membrane properties were unchanged: (1) the RMP (control, $-63 \pm 1.0 \mathrm{mV}, n=28 ; \mathrm{Kcnq} 2 \mathrm{cKO},-63 \pm$
$0.6 \mathrm{mV}, n=24 ; p=0.83 ; K c n q 3 \mathrm{cKO}$, $-65 \pm 0.8, n=23 ; p>0.05$, ANOVATukey's post hoc test), and (2) hyperpolarization activation current activity, as measured by the voltage sag that develops during a large hyperpolarizing step (sag ratio for $-100 \mathrm{pA}$ : control, $0.62 \pm 0.01$, $n=26$; Kcnq2 $c K O, 0.60 \pm 0.01, n=23$; Kcnq3 $3 K O, 0.63 \pm 1.3, n=21 ; p>0.05$, ANOVA). These data indicate that intrinsic membrane properties are largely unchanged by the loss of either Kcnq2 or Kcnq3.

\section{Differential dependence of global KCNQ channel activity on Kcnq2 and Kcnq3}

Although KCNQ2 and KCNQ3 are primarily expressed as KCNQ2/3 heteromers in neurons, they can also form homomers in heterologous cells to varying extents (Wang et al., 1998; Tatulian et al., 2001). The distinctive cellular phenotypes of Kcnq2-null and Kcnq3-null neurons raised the issue of the extent to which loss of one channel impairs expression of the other. To explore this question, we assayed the remaining KCNQ subunit protein levels in $K c n q 2$ cKO and Kcnq3 $c K O$ mice by quantitative fluorescent Western blotting. We found that in hippocampal membrane fractions from Kcnq2 $c K O$ mice, both KCNQ2 and KCNQ3 protein levels were greatly reduced by $\sim 75$ and $\sim 60 \%$, respectively (Fig. 5A). Importantly, despite the presence of $\sim 40 \%$ of the normal KCNQ3 protein levels in Kcnq2 cKO mice, KCNQ3 seems to contribute little to the $\mathrm{M}$ current, as the $\mathrm{M}$ current is reduced by $\sim 85 \%$ in Kcnq 2 cKO mice. We should also note that our membrane isolation protocol does not distinguish between plasma membrane fractions and endoplasmic reticulum (ER) membrane fractions. Therefore, the remaining KCNQ3 protein might reflect $\mathrm{KCNQ} 3$ residing in the ER, and explain why there is a greater loss of the $\mathrm{M}$ current.

In addition to KCNQ2 and KCNQ3 channels, pyramidal neurons also express KCNQ5 channels, which can either function as homomers or as heteromers with KCNQ3 channels (Lerche et al., 2000; Schroeder et al., 2000). Unexpectedly, we also observed a reduction of KCNQ5 protein levels in Kcnq2 cKO mice $(\sim 40 \%$ reduction; Fig. $5 A$ ). In contrast, we only observed a modest decrease in KCNQ2 and KCNQ5 protein levels $(\sim 15$ and $\sim 20 \%$ reduction, respectively) in hippocampi from Kcnq3 $c K O$ mice, despite $\sim 75 \%$ loss of KCNQ3. These results indicate that loss of KCNQ2 channels leads to a substantial reduction of all KCNQ channels in the hippocampus, while loss of KCNQ3 channels does not.

To corroborate the biochemical results, we determined the effects of KCNQ-specific allosteric activators on the spontaneous firing of CA1 pyramidal neurons. The use of allosteric activators was necessary as no KCNQ subtype-selective inhibitors are avail- 
able. If there is indeed a substantial decrease in KCNQ channels in Kcnq2 cKO and $K c n q 3$ cKO mice, these activators should be less able to inhibit tonic firing. For these experiments, we first used the cell-attached recording configuration to prevent any rundown of KCNQ-channel activity during prolonged recordings. Furthermore, the extracellular potassium concentration was increased from 2.5 to 8.5 $\mathrm{mm}$ to shift the potassium equilibrium potential to more depolarized values, leading to a higher tonic AP firing rate and enhancing the role of all KCNQ channels in regulating the pyramidal neuron firing rate (Vervaeke et al., 2006). These conditions increased the sensitivity of our measurements.

First, we used retigabine. Recently approved by the Food and Drug Administration, retigabine is a KCNQ channel agonist that activates KCNQ2, KCNQ3, and KCNQ5 channels. As with previous studies (Yue and Yaari, 2006; Hu et al., 2007), application of retigabine $(20 \mu \mathrm{M})$ completely inhibited the tonic firing of pyramidal neurons in control mice (Fig. $5 B$ ). In contrast, retigabine was much less effective in blocking the pyramidal neuron tonic firing activity in Kcnq2 $c K O$ mice, and slightly less effective in Kcnq3 cKO mice (percentage inhibition: control, $99.0 \pm 1 \%, n=8 ;{ }^{*} K c n q 2 c K O, 39 \pm 8 \%$, $n=12 ;{ }^{\star} K c n q 3 c K O, 71 \pm 9 \%, n=9 ;{ }^{\star} p<$ 0.05 vs control, ANOVA-Dunnett's post hoc test). This finding is consistent with our immunoblot data that showed a greater reduction of all KCNQ channels in Kcnq2 cKO mice compared with Kcnq3 cKO mice.

Next, we used the KCNQ2-selective agonist ICA-27243 $(25 \mu \mathrm{M})$, which activates KCNQ2 homomeric and heteromeric channels (Wickenden et al., 2008; Blom et al., 2010). As with retigabine, ICA-27243 silenced pyramidal neurons in control mice (Fig. 5B). In contrast, ICA-27243 did not inhibit tonic AP firing in Kcnq2-null neurons, but instead increased firing (Fig. $5 B$ ). This confirms that the inhibitory effects of ICA-27243 are due to the presence of KCNQ2 channels and indicates that ICA-27243 acts on a different target to depolarize neurons. We then used ICA-27243 as a probe for the presence of KCNQ2 channels in Kcnq3 cKO mice. Consistent with our biochemical data showing retention of KCNQ2 channels, ICA-27243 substantially reduced tonic firing rate in Kcnq3 cKO mice (percentage inhibition: control, $99.5 \pm 0.2 \%$, $n=8 ; K c n q 3$ cKO, $74 \pm 6 \%, n=7$; Fig. $5 B)$.

To confirm the presence of KCNQ2 channels in the Kcnq3null neurons using ICA-27243 free from any complications arising from nonspecific changes to membrane potential, we assessed its effect in current-clamp whole-cell configuration. We compared the firing properties of CA1 pyramidal neurons from control, Kcnq2 cKO, and Kcnq3 cKO mice by examining the number of APs elicited by $1 \mathrm{~s}$ current injections of various amplitudes and ANOVA $\left({ }^{*} p<0.05\right)$.
B
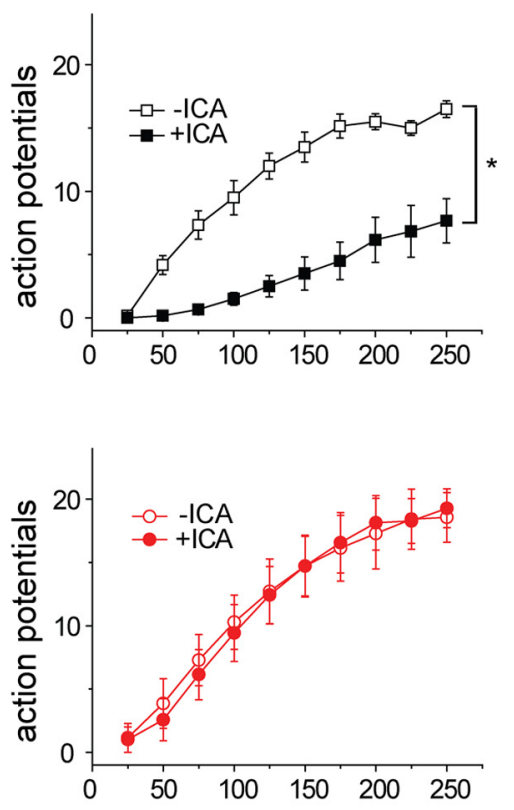

Kenq3 cKO

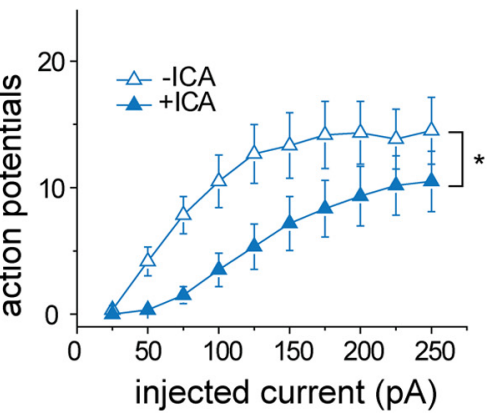

Figure 6. The KCNQ2 allosteric activator ICA-27243 inhibits AP firing in Kcnq3 CKO but not Kcnq2 cKO mice. A, Voltage responses to various current injection steps ( 1 s) in pyramidal neurons from either control, $K c n q 2 c K 0$, or Kcnq3 $c K 0$ mice. Membrane potential mmary graphs showing the effect of ICA-27243 on pyramidal neuron AP number in control $(n=6), \operatorname{Kcnq2} C \mathrm{KO}(n=7)$, or $K c n q 3$ CKO $(n=6)$ mice. Data shown are means \pm SEM. Statistical significance was determined by two-way repeated-measures

by holding the membrane potential at $-60 \mathrm{mV}$. As shown in Figure 6, the number of APs before and after application of ICA-27243 did not change in Kcnq2-null neurons, unlike ICA27243-treated pyramidal neurons in control and Kcnq3 cKO mice. This inhibition suggests that homomeric KCNQ2 channels are present and are readily engaged by KCNQ2 allosteric activators in the absence of KCNQ3 channels.

\section{Discussion}

The present study shows that KCNQ2 channels are indispensible for pyramidal neurons to control their excitability and can function independently of KCNQ3. Our work shows that loss of KCNQ2 channels leads to premature postnatal death and cortical hyperexcitability. The elevated CA1 pyramidal neuronal activity in Kcnq2 cKO mice is likely due to the severe concomitant reduction of KCNQ3 and KCNQ5 protein levels, smaller mAHP, and prolonged ADP. In contrast, Kcnq3 $c K O$ mice are viable and show little evidence of elevated neuronal activity in CA1 pyramidal neurons. Loss of KCNQ3 channels leads to a modest loss of KCNQ2 and 
KCNQ5 levels, and the use of KCNQ2 allosteric activators demonstrates that functional KCNQ2 channels remain in these mice. These findings clarify the role of KCNQ2 and KCNQ3 channels in controlling pyramidal neuron excitability, and may thereby give insight into their relative contributions to human pediatric epilepsies.

\section{Homeostatic adaptations in the absence of KCNQ2 or KCNQ3 channels}

We did not find any significant changes to either the RMP or $R_{\mathrm{N}}$ in neurons lacking KCNQ2 or KCNQ3, which is consistent with previous findings in mice with loss-of-function mutations in Kcnq2 or Kcnq3 and mice expressing dominantnegative KCNQ subunits (Peters et al., 2005; Singh et al., 2008). However, multiple pharmacological studies have shown that XE991, a selective KCNQ channel inhibitor, depolarizes neurons, allowing them to reach AP threshold quicker and more frequently (Yue and Yaari, 2004; Hu et al., 2007; Shah et al., 2008). The absence of changes to RMP and $R_{\mathrm{N}}$ in KCNQ-mutant mice therefore suggests that there may be homeostatic adaptations of intrinsic membrane properties in the absence of normally functioning KCNQ channels. This is supported by our observation that AP threshold was shifted to more depolarized membrane potentials in KCNQ2-null neurons, a direction counter to what one would expect for reducing a resting potassium conductance.

Homeostatic adaptation might also explain the near-normal $\mathrm{mAHP}$ and firing properties in the absence of KCNQ3 channels. KCNQ2/3 channels mediate the mAHP, a potassium-mediated hyperpolarization that typically activates following a brief surge of spiking activity (Storm, 1989; Peters et al., 2005). The mAHP is the primary limit on the ADP that follows AP firing, and it also contributes to spike frequency adaptation. Similar to the study of Peters et al. (2005) on the effect of KCNQ2 dominant-negative channels, we find that deletion of Kcnq2 from pyramidal neurons significantly reduces the mAHP, and thus prolongs the ADP and results in less spike frequency adaptation. In contrast, loss of KCNQ3 does not decrease the mAHP and, if anything, enhances the $\mathrm{mAHP}$ based on the significant acceleration of the ADP repolarization. These data indicate that although the MAHP is mediated by KCNQ2/3 heteromers in wild-type mice, homeostatic adaptations can support near-normal levels of the mAHP in the absence of KCNQ3, but not KCNQ2.

Like the mAHP, the $\mathrm{M}$ current is a potassium conductance primarily mediated by KCNQ2/3 heteromeric channels and is extremely sensitive to the loss of KCNQ2. However, in contrast to the $\mathrm{mAHP}$, we find that the M current is also sensitive to the loss of KCNQ3. For this conductance, other channels seem to only partially compensate for the loss of KCNQ3. Further studies will be necessary to fully understand the differential compensatory changes enacted to maintain the mAHP and M current after loss of KCNQ subunits.

In contrast to our current findings, we previously reported that loss of KCNQ3 channels does not impair M-current levels in CA1 pyramidal neurons (Tzingounis and Nicoll, 2008). One major difference between the two studies is the use of conditional versus constitutive Kcnq3 knock-out mice. In constitutive Kcnq3 knock-out mice, Kcnq3 deletion occurs throughout the nervous system and development, unlike the conditional knock-out mice used in the current study. Consequently, global versus conditional Kcnq3 deletion may engage different compensatory programs at the network level, leading to different effects on the M current.

\section{Trafficking differences may explain differential sensitivity to loss of KCNQ2 versus KCNQ3}

Nearly all of our experiments suggest that KCNQ2 channels, but not KCNQ3 channels, are required for pyramidal neurons to control their excitability. Although some of these differences may be due to divergent compensatory mechanisms at either the cellular or network level, differences in KCNQ2 versus KCNQ3 trafficking may explain some or all of the phenotypic disparities.

Our Western blotting results indicate that KCNQ3 protein levels critically depend on KCNQ2 channels, whereas KCNQ2 levels only modestly rely on KCNQ3 channels in hippocampal neurons. This suggests that KCNQ3 channels may be unable to exist as homomers, whereas KCNQ2 homomeric channels may functionally compensate for the loss of KCNQ2/3 channels. This interpretation is consistent with our pharmacological experiments demonstrating functional KCNQ2-containing channels in Kcnq3-null neurons. Prior studies on the ability of KCNQ2 channels to traffic and function as homomers have given mixed results. A report in heterologous cells showed that coexpression of KCNQ2 and KCNQ3 channels primarily leads to increased surface expression of KCNQ3 channels, but not of KCNQ2 channels (Surti et al., 2005). However, several others have reported that robust surface expression of exogenous KCNQ2 required coexpression with KCNQ3 channels in heterologous systems and in cultured neurons (Schwake et al., 2000; Etxeberria et al., 2004; Rasmussen et al., 2007). Our work clarifies this issue by showing that pyramidal neurons sustain the majority of native KCNQ2 channels in the absence of KCNQ3 channels.

Although the mechanism that leads to KCNQ3 protein loss in the absence of KCNQ2 is unknown, it was suggested that KCNQ3 channels have an ER retention motif that is masked by the presence of KCNQ2 channels (Nakajo and Kubo, 2008). It is possible that in the absence of KCNQ2 channels, accumulation of KCNQ3 channels in the ER activates the ER-associated degradation response and directs KCNQ3 channels to degradation pathways. KCNQ2 channels have not been shown to have such an ER retention motif; instead, several studies suggest that exiting of KCNQ2 from the ER relies on calmodulin (Gamper et al., 2005; Etxeberria et al., 2008; Alaimo et al., 2009; Kosenko et al., 2012). Thus, KCNQ2 channels may not strictly require KCNQ3 channels for ER exit, and this could explain why we see only modest KCNQ2 protein loss in the absence of KCNQ3. Future work is needed to identify the complete mechanism by which KCNQ2 and KCNQ3 levels are regulated in neurons.

Unexpectedly, there was also a $\sim 40 \%$ loss of KCNQ5 protein in Kcnq2 cKO mice. KCNQ5 and KCNQ2 do not form heteromeric channels (Lerche et al., 2000; Schroeder et al., 2000), and therefore, any effects of KCNQ2 on KCNQ5 should be indirect. KCNQ5 channels have been proposed to function as homomers and KCNQ3/5 heteromers. However, Kcnq3 cKO mice had only a modest loss of KCNQ5 protein, and thus the larger loss in Kcnq2 cKO mice is unlikely to be solely due to the reduction of KCNQ3 protein levels. One possibility is that the elevated cortical network activity in Kcnq2 cKO mice downregulates KCNQ3 and KCNQ5 channels; recent work has shown that seizure activity can decrease KCNQ protein levels in the brain (Maslarova et al., 2013). However, another study found that elevated excitability increases KCNQ2/3 mRNA transcripts (Zhang and Shapiro, 2012). Future studies are needed to clarify how KCNQ protein levels are affected by seizure activity, and whether this mechanism explains the loss of KCNQ5 in Kcnq2 cKO mice. 


\section{Possible clinical implications}

It is now well documented that mutations of Kcnq2 can lead to neurological disorders of varying severity, from BFNCs to neonatal epileptic encephalopathy, Ohtahara syndrome, and infantile spasms (Singh et al., 2003; Millichap and Cooper, 2012; Saitsu et al., 2012; Weckhuysen et al., 2012; Allen et al., 2013). In contrast, disease-causing mutations in Kcnq3 are much less frequent and have been predominantly associated with BFNCs (Maljevic et al., 2008). Although our conditional Kcnq2 and Kcnq 3 mice are not exact models of KCNQ channelopathies, they might still provide insight for the prevalence of Kcnq2-related pediatric epilepsy disorders.

Our work suggests that Kcnq2 truncation or trafficking mutations also impair the activity of KCNQ2/3, and possibly of KCNQ5 channels. Such a broad loss of KCNQ channel function is likely to lead to hyperexcitability. Indeed, some epilepsyassociated mutations in Kcnq2 prevent normal KCNQ2 surface expression (Schwake et al., 2000; Maljevic et al., 2010; Orhan et al., 2013). On the other hand, our work suggests that Kcnq3 mutations might not significantly reduce KCNQ2 and KCNQ5 channel levels in pyramidal neurons, allowing the remaining KCNQ channels to function and dampen neuronal excitability. Consistent with this hypothesis, truncation or trafficking mutations in Kcnq3 have not been identified in BFNC patients (Maljevic et al., 2010). Instead, the handful of identified Kcnq3 mutations in BFNC patients (Maljevic et al., 2010) and in a patient with epileptic encephalopathy (Allen et al., 2013) involve domains important for gating and ion conduction. Such mutations will alter the biophysical properties of $\mathrm{KCNQ} 2 / 3$ channels.

In summary, our work demonstrates that KCNQ2 channels are obligatory components of KCNQ channels in pyramidal neurons and are likely sufficient to maintain pyramidal neuron firing properties at near-normal levels in the absence of KCNQ2/3 channels.

\section{References}

Alaimo A, Gómez-Posada JC, Aivar P, Etxeberría A, Rodriguez-Alfaro JA, Areso P, Villarroel A (2009) Calmodulin activation limits the rate of KCNQ2 K+ channel exit from the endoplasmic reticulum. J Biol Chem 284:20668-20675. CrossRef Medline

Allen AS, Berkovic SF, Cossette P, Delanty N, Dlugos D, Eichler EE, Epstein MP, Glauser T, Goldstein DB, Han Y, Heinzen EL, Hitomi Y, Howell KB, Johnson MR, Kuzniecky R, Lowenstein DH, Lu YF, Madou MR, Marson AG, Mefford HC, et al. (2013) De novo mutations in epileptic encephalopathies. Nature 501:217-221. CrossRef Medline

Ballester-Rosado CJ, Albright MJ, Wu CS, Liao CC, Zhu J, Xu J, Lee LJ, Lu HC (2010) mGluR5 in cortical excitatory neurons exerts both cellautonomous and -nonautonomous influences on cortical somatosensory circuit formation. J Neurosci 30:16896-16909. CrossRef Medline

Bean BP (2007) The action potential in mammalian central neurons. Nat Rev Neurosci 8:451-465. CrossRef Medline

Blom SM, Schmitt N, Jensen HS (2010) Differential effects of ICA-27243 on cloned K(V)7 channels. Pharmacology 86:174-181. CrossRef Medline

Charlier C, Singh NA, Ryan SG, Lewis TB, Reus BE, Leach RJ, Leppert M (1998) A pore mutation in a novel KQT-like potassium channel gene in an idiopathic epilepsy family. Nat Genet 18:53-55. CrossRef Medline

Cooper EC, Harrington E, Jan YN, Jan LY (2001) M channel KCNQ2 subunits are localized to key sites for control of neuronal network oscillations and synchronization in mouse brain. J Neurosci 21:9529-9540. Medline

Etxeberria A, Santana-Castro I, Regalado MP, Aivar P, Villarroel A (2004) Three mechanisms underlie KCNQ2/3 heteromeric potassium M-channel potentiation. J Neurosci 24:9146-9152. CrossRef Medline

Etxeberria A, Aivar P, Rodriguez-Alfaro JA, Alaimo A, Villacé P, GómezPosada JC, Areso P, Villarroel A (2008) Calmodulin regulates the trafficking of KCNQ2 potassium channels. FASEB J 22:1135-1143. Medline

Gamper N, Li Y, Shapiro MS (2005) Structural requirements for differential sensitivity of KCNQ K+ channels to modulation by $\mathrm{Ca} 2+/$ calmodulin. Mol Biol Cell 16:3538-3551. CrossRef Medline

Gorski JA, Talley T, Qiu M, Puelles L, Rubenstein JL, Jones KR (2002) Cortical excitatory neurons and glia, but not GABAergic neurons, are produced in the Emx1-expressing lineage. J Neurosci 22:6309-6314. Medline

Gu N, Vervaeke K, Hu H, Storm JF (2005) Kv7/KCNQ/M and HCN/h, but not KCa2/SK channels, contribute to the somatic medium afterhyperpolarization and excitability control in CA1 hippocampal pyramidal cells. J Physiol 566:689-715. CrossRef Medline

Gu N, Hu H, Vervaeke K, Storm JF (2008) SK (KCa2) channels do not control somatic excitability in CA1 pyramidal neurons but can be activated by dendritic excitatory synapses and regulate their impact. J Neurophysiol 100:2589-2604. CrossRef Medline

Hu H, Vervaeke K, Storm JF (2007) M-channels (Kv7/KCNQ channels) that regulate synaptic integration, excitability, and spike pattern of CA1 pyramidal cells are located in the perisomatic region. J Neurosci 27:18531867. CrossRef Medline

Ishii A, Miyajima T, Kurahashi H, Wang JW, Yasumoto S, Kaneko S, Hirose S (2012) KCNQ2 abnormality in BECTS: benign childhood epilepsy with centrotemporal spikes following benign neonatal seizures resulting from a mutation of KCNQ2. Epilepsy Res 102:122-125. CrossRef Medline

Jentsch TJ (2000) Neuronal KCNQ potassium channels: physiology and role in disease. Nat Rev Neurosci 1:21-30. CrossRef Medline

Kosenko A, Kang S, Smith IM, Greene DL, Langeberg LK, Scott JD, Hoshi N (2012) Coordinated signal integration at the M-type potassium channel upon muscarinic stimulation. EMBO J 31:3147-3156. CrossRef Medline

Lawrence JJ, Saraga F, Churchill JF, Statland JM, Travis KE, Skinner FK, McBain CJ (2006) Somatodendritic Kv7/KCNQ/M channels control interspike interval in hippocampal interneurons. J Neurosci 26:1232512338. CrossRef Medline

Lerche C, Scherer CR, Seebohm G, Derst C, Wei AD, Busch AE, Steinmeyer K (2000) Molecular cloning and functional expression of KCNQ5, a potassium channel subunit that may contribute to neuronal M-current diversity. J Biol Chem 275:22395-22400. CrossRef Medline

Liu X, Fagotto F (2011) A method to separate nuclear, cytosolic, and membrane-associated signaling molecules in cultured cells. Sci Signal 4:pl2. CrossRef Medline

Maljevic S, Wuttke TV, Lerche H (2008) Nervous system KV7 disorders: breakdown of a subthreshold brake. J Physiol 586:1791-1801. CrossRef Medline

Maljevic S, Wuttke TV, Seebohm G, Lerche H (2010) K(V)7 channelopathies. Pflugers Arch 460:277-288. CrossRef

Maslarova A, Salar S, Lapilover E, Friedman A, Veh RW, Heinemann U (2013) Increased susceptibility to acetylcholine in the entorhinal cortex of pilocarpine-treated rats involves alterations in KCNQ channels. Neurobiol Dis 56:14-24. CrossRef Medline

Millichap JJ, Cooper EC (2012) KCNQ2 potassium channel epileptic encephalopathy syndrome: divorce of an electro-mechanical couple? Epilepsy Curr 12:150-152. CrossRef Medline

Nakajo K, Kubo Y (2008) Second coiled-coil domain of KCNQ channe controls current expression and subfamily specific heteromultimerization by salt bridge networks. J Physiol 586:2827-2840. CrossRef Medline

Nieto-Gonzalez JL, Jensen K (2013) BDNF depresses excitability of parvalbumin-positive interneurons through an M-like current in rat dentate gyrus. PLoS One 8:e67318. CrossRef Medline

Orhan G, Bock M, Schepers D, Ilina EI, Reichel SN, Loffler H, Jezutkovic N, Weckhuysen S, Mandelstam S, Suls A, Danker T, Guenther E, Scheffer IE, Jonghe PD, Lerche H, Maljevic S (2013) Dominant-negative effects of KCNQ2 mutations are associated with epileptic encephalopathy. Ann Neurol. Advance online publication. Retrieved March 12, 2014. CrossRef Medline

Otto JF, Yang Y, Frankel WN, White HS, Wilcox KS (2006) A spontaneous mutation involving Kcnq2 (Kv7.2) reduces M-current density and spike frequency adaptation in mouse CA1 neurons. J Neurosci 26:2053-2059. CrossRef Medline

Peters HC, Hu H, Pongs O, Storm JF, Isbrandt D (2005) Conditional transgenic suppression of $\mathrm{M}$ channels in mouse brain reveals functions in neuronal excitability, resonance and behavior. Nat Neurosci 8:51-60. CrossRef Medline

Rasmussen HB, Frøkjaer-Jensen C, Jensen CS, Jensen HS, Jørgensen NK, Misonou H, Trimmer JS, Olesen SP, Schmitt N (2007) Requirement of 
subunit co-assembly and ankyrin-G for M-channel localization at the axon initial segment. J Cell Sci 120:953-963. CrossRef Medline

Saitsu H, Kato M, Koide A, Goto T, Fujita T, Nishiyama K, Tsurusaki Y, Doi H, Miyake N, Hayasaka K, Matsumoto N (2012) Whole exome sequencing identifies KCNQ2 mutations in Ohtahara syndrome. Ann Neurol 72:298-300. CrossRef Medline

Schroeder BC, Hechenberger M, Weinreich F, Kubisch C, Jentsch TJ (2000) KCNQ5, a novel potassium channel broadly expressed in brain, mediates M-type currents. J Biol Chem 275:24089-24095. CrossRef Medline

Schwake M, Pusch M, Kharkovets T, Jentsch TJ (2000) Surface expression and single channel properties of KCNQ2/KCNQ3, M-type K+ channels involved in epilepsy. J Biol Chem 275:13343-13348. CrossRef Medline

Shah MM, Migliore M, Valencia I, Cooper EC, Brown DA (2008) Functional significance of axonal Kv7 channels in hippocampal pyramidal neurons. Proc Natl Acad Sci U S A 105:7869-7874. CrossRef Medline

Singh NA, Charlier C, Stauffer D, DuPont BR, Leach RJ, Melis R, Ronen GM, Bjerre I, Quattlebaum T, Murphy JV, McHarg ML, Gagnon D, Rosales TO, Peiffer A, Anderson VE, Leppert M (1998) A novel potassium channel gene, KCNQ2, is mutated in an inherited epilepsy of newborns. Nat Genet 18:25-29. CrossRef Medline

Singh NA, Westenskow P, Charlier C, Pappas C, Leslie J, Dillon J, Anderson VE, Sanguinetti MC, Leppert MF, Consortium BP (2003) KCNQ2 and KCNQ3 potassium channel genes in benign familial neonatal convulsions: expansion of the functional and mutation spectrum. Brain 126: 2726-2737. CrossRef Medline

Singh NA, Otto JF, Dahle EJ, Pappas C, Leslie JD, Vilaythong A, Noebels JL, White HS, Wilcox KS, Leppert MF (2008) Mouse models of human KCNQ2 and KCNQ3 mutations for benign familial neonatal convulsions show seizures and neuronal plasticity without synaptic reorganization. J Physiol 586:3405-3423. CrossRef Medline

Storm JF (1989) An after-hyperpolarization of medium duration in rat hippocampal pyramidal cells. J Physiol 409:171-190. Medline

Surti TS, Huang L, Jan YN, Jan LY, Cooper EC (2005) Identification by mass spectrometry and functional characterization of two phosphorylation sites of KCNQ2/KCNQ3 channels. Proc Natl Acad Sci U S A 102:1782817833. CrossRef Medline

Tatulian L, Delmas P, Abogadie FC, Brown DA (2001) Activation of ex- pressed KCNQ potassium currents and native neuronal M-type potassium currents by the anti-convulsant drug retigabine. J Neurosci 21: 5535-5545. Medline

Tzingounis AV, Nicoll RA (2008) Contribution of KCNQ2 and KCNQ3 to the medium and slow afterhyperpolarization currents. Proc Natl Acad Sci U S A 105:19974-19979. CrossRef Medline

Vervaeke K, Gu N, Agdestein C, Hu H, Storm JF (2006) Kv7/KCNQ/Mchannels in rat glutamatergic hippocampal axons and their role in regulation of excitability and transmitter release. J Physiol 576:235-256. CrossRef Medline

Wang HS, Pan Z, Shi W, Brown BS, Wymore RS, Cohen IS, Dixon JE, McKinnon D (1998) KCNQ2 and KCNQ3 potassium channel subunits: molecular correlates of the M-channel. Science 282:1890-1893. CrossRef Medline

Watanabe H, Nagata E, Kosakai A, Nakamura M, Yokoyama M, Tanaka K, Sasai H (2000) Disruption of the epilepsy KCNQ2 gene results in neural hyperexcitability. J Neurochem 75:28-33. Medline

Weckhuysen S, Mandelstam S, Suls A, Audenaert D, Deconinck T, Claes LR, Deprez L, Smets K, Hristova D, Yordanova I, Jordanova A, Ceulemans B, Jansen A, Hasaerts D, Roelens F, Lagae L, Yendle S, Stanley T, Heron SE, Mulley JC et al. (2012) KCNQ2 encephalopathy: emerging phenotype of a neonatal epileptic encephalopathy. Ann Neurol 71:15-25. CrossRef Medline

Wickenden AD, Krajewski JL, London B, Wagoner PK, Wilson WA, Clark S, Roeloffs R, McNaughton-Smith G, Rigdon GC (2008) N-(6-chloropyridin-3-yl)-3,4-difluoro-benzamide (ICA-27243): a novel, selective KCNQ2/Q3 potassium channel activator. Mol Pharmacol 73:977-986. Medline

Yue C, Yaari Y (2004) KCNQ/M channels control spike afterdepolarization and burst generation in hippocampal neurons. J Neurosci 24:4614-4624. CrossRef Medline

Yue C, Yaari Y (2006) Axo-somatic and apical dendritic Kv7/M channels differentially regulate the intrinsic excitability of adult rat CA1 pyramidal cells. J Neurophysiol 95:3480-3495. CrossRef Medline

Zhang J, Shapiro MS (2012) Activity-dependent transcriptional regulation of M-Type (Kv7) K(+) channels by AKAP79/150-mediated NFAT actions. Neuron 76:1133-1146. CrossRef Medline 